\title{
APOIO À GESTÃO DE DESEMPENHO DO PROGRAMA DE TREINAMENTO VIA MOODLE: ESCOLA DE ADMINISTRAÇÃO PÚBLICA DO ESTADO DE SANTA CATARINA
}

\author{
SUPPORT FOR THE PERFORMANCE MANAGEMENT OF THE VIA MOODLE TRAINING \\ PROGRAM: SCHOOL OF PUBLIC ADMINISTRATION OF THE STATE OF SANTA \\ CATARINA
}

\author{
Bárbara Gonçalves do Amaral ${ }^{1}$ \\ Universidade Federal de Santa Catarina \\ baah.amaral@outlook.com
}

\author{
Sandra Rolim Ensslin \\ Universidade Federal de Santa Catarina \\ sensslin@gmail.com
}

\begin{abstract}
RESUMO
Esse artigo apresenta um modelo de avaliação de desempenho desenvolvido para avaliar o desempenho do programa de treinamento de uma escola de governo estadual para subsidiar a tomada de decisão dos gestores responsáveis. A metodologia Multicritério de Apoio à DecisãoConstrutivista MCDA-C norteou a pesquisa. Por meio de entrevistas semiestruturadas com os decisores da Diretoria da Escola de Administração Pública (DEAP), foram identificados 38 Elementos Primários de Avaliação-EPA. Esses foram desmembrados em 60 conceitos, que foram agrupados nas áreas de preocupação: Gestão da evasão; Temas dos cursos; Criação das parcerias; e Gestão interna. Para avaliar o desempenho do Programa de Treinamento da DEAP, foram construídos 39 descritores. O modelo foi considerado, pelos decisores da DEAP, legítimo ao contemplar suas preocupações e os aspectos ambientais que compreendem seu contexto de gestão. Em termos teóricos esta pesquisa demonstra a potencialidade dos dois instrumentos metodológicos utilizados para construção de conhecimento junto aos decisores e as pesquisadoras.
\end{abstract}

Palavras-chave: Avaliação de Desempenho. Gestão Pública. Programas de Treinamento. Abordagem Construtivista.

\section{ABSTRACT}

The research aims to evaluate the performance of a training program of a state government school to support the decision making of the responsible managers. The MCDA-C Multicriteria for Decision Support-Constructivist methodology guided the research. Through semistructured interviews, the decision makers of the Board of the School of Public Administration

\footnotetext{
${ }^{1}$ Endereço contato: Tomaz José Oliveira, 65. Bairro Rio Vermelho. CEP 88060427 - Florianópolis, SC.
} 
(DEAP), 38 Primary Elements of Assessment were identified. These were broken down into 60 concepts, which were grouped into the areas of concern: Avoidance management; Course themes; Creation of partnerships; and Internal management. To assess the performance of the DEAP Training Program, 39 descriptors were built. The model was considered legitimate by DEAP decision makers when considering their concerns and the environmental aspects that comprise their management context. In theoretical terms, this research seeks to demonstrate the potential of the two methodological instruments used to build knowledge with decision makers and researchers.

Keywords: Performance Evaluation. Public Management. Training Programs. Constructivist Approach.

\section{INTRODUÇÃO}

A Administração Pública demanda competências adequadas para atender às necessidades de seu aparato estatal e da sociedade. Essas necessidades seriam, sobretudo, a melhoria da eficiência e eficácia dos serviços públicos prestados (Sims, 1993). Para oferta de bens e serviços públicos de qualidade à sociedade, a Administração Pública tem os servidores públicos como agentes essenciais. Uma das formas de a gestão pública assegurar o desenvolvimento permanente do servidor é fazer uso da estratégia de capacitá-los por meio de programas de treinamentos (Sims, 1993; Healy, 2001; Huque \& Vyas, 2008; Suliyanto \& Setyawati, 2015; Kucherov \& Manokhina, 2017). Assim, os programas de treinamento, ao promoverem o aperfeiçoamento e a atualização do capital intelectual dos profissionais, contribuem para o desenvolvimento das competências institucionais (Tasca, Ensslin, Ensslin, \& Alves, 2010; Suliyanto \& Setyawati, 2015; Kucherov \& Manokhina, 2017).

Na gestão pública do Estado de Santa Catarina, os programas de treinamento podem ser ofertados pelas Escolas Virtuais de Administração Pública, que propiciam aos servidores obterem um conjunto de conhecimentos, habilidades e atitudes imperativas no desempenho de suas atividades profissionais (Portal do Servidor, 2018).

Dada a capacidade dessas Escolas Virtuais interferirem na dinâmica e qualidade da prestação de serviços públicos e no desempenho dos servidores, há a necessidade de um processo de avaliação de seus Programas de Treinamento (Tasca et al., 2010). A Avaliação de Programas de Treinamento proporciona aos gestores públicos mensurar a efetividade de seus programas e, consequentemente, determinar para a instituição o valor que o treinamento agrega ao serviço prestado (Healy, 2001, Huque \& Vyas, 2008; Suliyanto \& Setyawati, 2015; Lee, Jean, Kim, \& Lee, 2017). Adicionalmente, a mensuração contribui para apoiar a gestão do Programa de Treinamento ao propiciar feedback para os gestores e planejadores do mesmo (Sims, 1993; Healy, 2001; Huque \& Vyas, 2008; Suliyanto \& Setyawati, 2015; Lee et al., 2017).

Devido à ausência de um instrumento, há lacunas de modelos de avaliação de programas de treinamento desenvolvidos especificamente para escolas de governo. A DEAP Virtual, gerenciada pela Diretoria da Escola de Administração Pública (DEAP) do Estado de Santa Catarina, não consegue identificar em que aspectos o programa apresenta desempenho aquém do esperado, uma vez que não possui indicadores de avaliação. A falta de indicadores na avaliação do Programa da DEAP, segundo sua gestora, inibe um conhecimento mais aprofundado sobre os seus processos internos que, por sua vez, prejudicam a identificação do que pode ser aperfeiçoado no programa e, consequentemente, o engajamento da DEAP no envolvimento de novas políticas internas. Dessa forma, a avaliação do Programa de Treinamento da DEAP ocasionaria um diagnóstico perante a qualidade, a necessidade e as limitações do programa, permitindo o monitoramento e aperfeiçoamento (gestão) dos aspectos avaliados. 
Diante desse contexto, emerge a questão que norteia a pesquisa aqui desenvolvida: quais aspectos devem ser levados em consideração para avaliar o desempenho do programa de treinamento de uma escola de governo estadual para subsidiar a tomada de decisão dos gestores responsáveis? Para responder a essa questão, este estudo construiu um modelo de Avaliação de Desempenho, focando em uma abordagem epistemológica Construtivista para apoiar a Gestão do Programa de Treinamento, via Moodle, da Secretaria de Estado da Administração de Santa Catarina (SEA-SC), segundo as necessidades e percepções da gestora da Diretoria da Escola de Administração Pública (DEAP).

Cumpre observar que a pesquisa respalda sua justificativa nos seis critérios de Sampieri, Collado e Lucio (2013) para avaliar sua utilidade, sendo eles: conveniência, relevância social, implicações práticas, valor teórico, utilidade metodológica e viabilidade em relação ao tempo, recursos e habilidades.

Quanto à conveniência, a pesquisa é oportuna por buscar uma abordagem mais interpretativa e menos funcionalista para compreender a Avaliação de Desempenho da DEAP, posto que a literatura de Avaliação de Desempenho carece de tais pesquisas (Bititci, Garengo, Dörfler, \& Nudurupati, 2012).

Em relação à relevância social, a pesquisa evidencia informações sobre a eficiência dos programas de treinamento em relação ao desenvolvimento de seus servidores. Assim, ao avaliar os Programas de Treinamento é possível identificar seus pontos frágeis, aperfeiçoando-os de acordo com o alinhamento estratégico da instituição, a fim de promover qualidade nos serviços públicos prestados.

No que se refere às implicações práticas, esta pesquisa auxilia na proposta de um modelo para subsidiar tomada de decisão de gestores sobre programas de treinamento de escolas de governo.

Quanto ao valor teórico, a pesquisa pretende explorar a lacuna na área de Avaliação de Programas de Treinamento (Tasca, Ensslin, \& Ensslin, 2012). Esta pesquisa foca o processo de gestão interna do Programa de Treinamento da DEAP, entretanto, de forma indireta, o aperfeiçoamento do Programa promove a aprendizagem dos servidores submetidos ao treinamento, atendendo assim, ao clamor de vários estudos (Moffie, Calhoon, \& O'brien, 1964; Mann \& Robertson, 1996; Healy, 2001; Alvarez, Salas, \& Garofano, 2004; Birdi, 2005; Schröeder et al., 2005; Wang \& Wilcox, 2006; Steensma \& Groeneveld, 2010; Tasca, Ensslin, \& Ensslin, 2012; Grohmann \& Kauffeld, 2013; Camolesi \& Cremonezi, 2015; Suliyanto \& Setyawati, 2015; Jeschke et al., 2017; Muhaisen \& Asour, 2017; Lucas et al., 2017; Rahim, 2017). Assim, aprendizagem é o produto do treinamento, mas não é a única variável que representa a qualidade do Programa para os decisores da DEAP.

Ademais, com o desenvolvimento da análise criteriosa do tema, foi possível sugerir oportunidades futuras. Com a utilização do Knowledge Development Process- Constructivist (ProKnow-C) - instrumento para seleção e análise crítica da literatura -, observaram-se poucos estudos sobre Avaliação de Programas de Treinamento com foco em Educação a Distância (Schröeder et al., 2005). Embora estes estudos nacionais que abordam o tema investigado não sigam uma abordagem interpretativista. Dessa forma, esta pesquisa sana essa lacuna ao avaliar Programas de Treinamento no contexto da Educação a Distância por meio de uma abordagem epistemológica construtivista. Outra lacuna encontrada na literatura é a carência de estudos relacionando Avaliação de Desempenho Organizacional à Avaliação de Programas de Treinamento (Tasca, Ensslin, \& Ensslin, 2012).

Adicionalmente, cumpre salientar o fato de que esta pesquisa, em termos teóricos, demonstra a potencialidade dos dois instrumentos metodológicos (ProKnow-C e metodologia Multicritério de Apoio à Decisão-Construtivista - MCDA-C) utilizados para a construção de conhecimento junto aos decisores (diretora e administrador) e as pesquisadoras. Em relação à utilidade metodológica, as pesquisadoras seguiram uma abordagem Construtivista nos 
procedimentos metodológicos, a fim de respeitar as preferências da gestora (diretora da DEAP) e expandirem seus conhecimentos. Esta metodologia possibilita a geração de conhecimento e aprendizagem no decisor. Argumenta-se que a pesquisa é viável para os interesses dos decisores (diretora da DEAP e administrador da SEA), na construção do instrumento de gestão.

A presente pesquisa destina-se à construção de um modelo de avaliação de desempenho qualitativo sob a perspectiva epistemológico-construtivista para auxiliar a gestora da DEAP, onde o estudo de caso foi desenvolvido. Essa perspectiva resulta em um modelo construído com base nas percepções, valores e motivações dos decisores atuais. Evidencia-se também como delimitação a execução da primeira e da terceira fase da metodologia MCDA-C: a Fase de Estruturação e a Fase de Recomendações.

\section{REFERENCIAL TEÓRICO}

As organizações complexas percebem os Programas de Treinamento como vantagem competitiva para capacitar seus colaboradores conforme as necessidades de seu ambiente volátil. Tal afirmação corrobora o pensamento que tais Programas de Treinamento têm a capacidade de impactar de forma positiva no desempenho individual e, por fim, no desempenho organizacional (Lingham, Richley, \& Rezania, 2006; Grohmann \& Kauffeld, 2013; Suliyanto \& Setyawati, 2015). Para assegurar a eficiência dos Programas de Treinamento, as organizações necessitam passar por processos de avaliação (House \& Tosi, 1963; Tasca et al., 2010; Grohmann \& Kauffeld, 2013).

Os processos de avaliação de Programas de Treinamento buscam apoiar a gestão e sua tomada de decisão, fornecendo um processo sistemático de coleta de informações relevantes e tempestivas (Sims, 1993; Mann \& Robertson, 1996; Birdi, 2005; Wang \& Wilcox, 2006; Ghosh et al., 2011; Rahim, 2017). Essa avaliação possibilita identificar as necessidades e deficiências do Programa e determinar sua eficácia e eficiência para a organização (Birdi, 2005; Lucas et al., 2017; Muhaisen \& Asour, 2017). Isto propicia para a gestão a melhora na qualidade do Programa (Kucherov \& Manokhina, 2017).

A avaliação do Programa de treinamento com foco em garantir a qualidade do Programa visa utilizar diferentes estratégias, tais como revisar os conteúdos instrucionais, a equipe de treinadores, as técnicas, dentre outros, para otimizar o Programa de Treinamento (Honeycutt \& Stevenson, 1989; Kuprenas, Madjidi, \& Alexander, 1999; Al-Athari \& Zairi, 2002; Birdi, 2005; Curado \& Teixeira, 2014). Entretanto Rahim (2017) aconselha aos gestores do Programa que, antes de aplicar qualquer estratégia, devem rever a necessidade da organização.

Para avaliar o Programa, a organização e o gestor do Programa, além de levarem em conta a necessidade e a utilidade do Programa no planejamento, também precisam compreender quais elementos devem ser avaliados (Healy, 2001; Tennant, Boonkrong, \& Roberts, 2002). A Figura 1 demonstra os elementos que compõem essa Avaliação.

Além da preocupação de compreender quais elementos compõem a avaliação, Al-Athari e Zairi (2002) salientam que cada avaliação deve considerar as particularidades do Programa. Entretanto nessa área, as organizações implementam ferramentas já padronizadas no mercado, por vezes, devido a limitação de recursos (Wang \& Wilcox, 2006). 


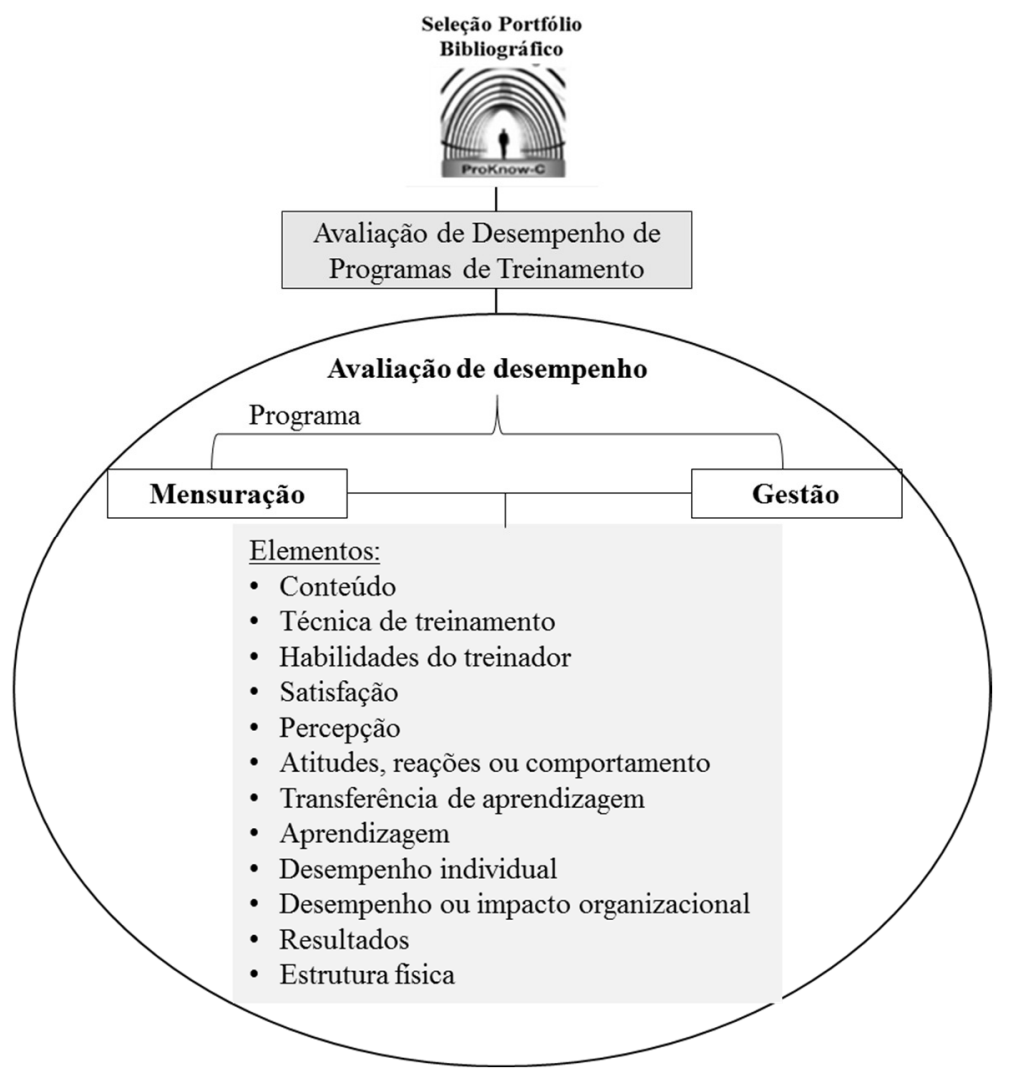

Figura 1. Elementos encontrados na literatura

Fonte: Dados da pesquisa.

Na Tabela 1, são apresentadas as ferramentas de avaliação de desempenho de programas de treinamento encontradas na literatura. Sendo que estes 22 artigos da Tabela 1 fazem parte dos 28 artigos do PB, mas nem todos os artigos do PB apresentaram ferramentas de avaliação de programa de treinamento.

Tabela 1. Ferramentas de avaliação de desempenho de programas de treinamento

\begin{tabular}{|l|l|}
\hline \multicolumn{1}{|c|}{ Estudos (Autor-ano) } & \multicolumn{1}{|c|}{ Ferramentas } \\
\hline $\begin{array}{l}\text { House e Tosi (1963); Birdi (2005); Huque e Vyas } \\
\text { (2008); Abbad, Corrêa e Meneses (2010); Ghosh et } \\
\text { al. (2011); Grohmann e Kauffeld (2013); Muhaisen } \\
\text { e Asour (2017); Rahim (2017) }\end{array}$ & Questionário \\
\hline Moffie, Calhoon e O'brien (1964) & $\begin{array}{l}\text { Avaliação envolve três instrumentos: Questionário de fim } \\
\text { de curso, avaliação de pensamento crítico de Watson- } \\
\text { Glaser e Situações Problemáticas e Registros } \\
\text { Observacionais de Participação em Grupos de Trabalho }\end{array}$ \\
\hline $\begin{array}{l}\text { Kirkpatrick (1979); Mann e Robertson (1996); } \\
\text { Curado e Teixeira (2011) }\end{array}$ & $\begin{array}{l}\text { Modelo de Kirkpatrick } \\
\text { Kuprenas, Madjidi e Alexander (1999) }\end{array}$ \\
\hline Tennant, Boonkrong e Roberts (2002) & $\begin{array}{l}\text { Multiple-level Training Assessment Model - Modelo de } \\
\text { avaliação de treinamento de vários níveis (tradução nossa) }\end{array}$ \\
\hline Alvarez, Salas e Garofano (2004) & $\begin{array}{l}\text { Training Programme Measurement Model - Modelo de } \\
\text { Mensuração do Programa de Treinamento (tradução } \\
\text { nossa) }\end{array}$ \\
\hline
\end{tabular}




\begin{tabular}{|l|l|}
$\begin{array}{l}\text { Carvalho e Abbad (2006); Coelho Junior (2010) e } \\
\text { Abbad; Dias e Guimarães (2016) }\end{array}$ & $\begin{array}{l}\text { Adaptação do Modelo IMPACT - Modelo Integrado de } \\
\text { Avaliação do Impacto do Treinamento no Trabalho } \\
\text { (tradução nossa) }\end{array}$ \\
\hline Lingham, Richley e Rezania (2006) & $\begin{array}{l}\text { Four-phase Evaluation System - Sistema de avaliação de } \\
\text { quatro fases (tradução nossa) }\end{array}$ \\
\hline Wang e Wilcox (2006) & $\begin{array}{l}\text { Framework for Summative Evaluation Phase Within } \\
\text { Systematic Training - Estrutura para a fase de avaliação } \\
\text { somativa no treinamento sistemático (tradução nossa) }\end{array}$ \\
\hline Meneses e Abbad (2009) & Modelos Lógicos \\
\hline Suliyanto e Setyawati (2015); Lucas et al. (2017) & $\begin{array}{l}\text { Analytical Hierarchy Process - Processo de Hierarquia } \\
\text { Analítica (tradução nossa) }\end{array}$ \\
\hline Jeschke et al. (2017) & $\begin{array}{l}\text { Avaliação baseou-se nos elementos de avaliação de } \\
\text { processos de Saunders et al. (2005) }\end{array}$ \\
\hline Lee et al. (2017) & $\begin{array}{l}\text { Success Case Method - Método de Caso de Sucesso } \\
\text { (tradução nossa) }\end{array}$ \\
\hline
\end{tabular}

Fonte: Dados da pesquisa.

Os questionários e os modelos mencionados na Tabela 1 utilizaram preceitos desenvolvidos pelo Modelo de Kirkpatrick, especialmente no primeiro e segundo nível. Esses questionários aplicaram a escala ordinal desenvolvida por Likert (1932), para captar a opinião do colaborador principalmente a respeito de sua satisfação com o conteúdo, a estrutura e o aprendizado.

Para Moffie, Calhoon e O'brien (1964), o programa foi avaliado com base em testes psicométricos que se concentra na percepção e reação dos colaboradores ao estruturar e fundamentar o pensamento crítico. Esta avaliação do programa focalizou nas habilidades cognitivas dos colaboradores obtidas no treinamento.

A Avaliação de Quatro Níveis, de Kirkpatrick (1979), mais conhecida como Modelo de Kirkpatrick, é composta pelos níveis: Reação, Aprendizagem, Comportamento e Resultados, que avalia os resultados obtidos com o treinamento. Isso acarreta planejar e integrar todo o processo de avaliação nesses níveis para que se compreenda qual informação se pretende coletar, onde, como e quando (Kirkpatrick, 1979). O nível Reação concentra-se na satisfação dos participantes com o treinamento (Kirkpatrick, 1979). O nível Aprendizagem representa o quanto os participantes adquirem de conhecimento, habilidades e atitude no treinamento (Kirkpatrick, 1979). O nível Comportamento traduz aplicação do aprendizado dos participantes em seus cargos/funções no trabalho (Kirkpatrick, 1979). E o nível Resultados mensura o resultado do treinamento e mede a eficácia da aprendizagem no desempenho da organização (Kirkpatrick, 1979). Destaca-se que o modelo se preocupa com a falta de medidas de propriedades psicométricas e não em considerar os fatores ambientais ou fatores contextuais circundantes que interferem no desempenho (Lee et al., 2017).

O modelo proposto por Kuprenas, Madjidi e Alexander (1999), nomeado Multiple-level Training Assessment Model, avalia o sucesso do Programa focando no processo de aprendizagem dos agentes envolvidos, por meio de quatro níveis: (i) 'mensuração da instrução', cujo foco é compreender quão bem foram utilizados a estrutura e os recursos (humanos e materiais) do Programa para aprendizagem; (ii) 'mensuração da aprendizagem' pelos participantes, cujo foco é verificar se houve absorção do conteúdo por eles; (iii) 'retenção da aprendizagem' onde é auferido o controle; e, (iv) ‘utilização da aprendizagem' que verifica se o aprendizado está sendo usado na organização.

O modelo proposto por Tennant, Boonkrong e Roberts (2002) baseia-se na combinação dos modelos de Kirkpatrick (1979) e CIRO (Context, Input, Reaction and Outcome). O modelo CIRO desenvolvido por Hamblin (1974) avalia o contexto, a partir da definição dos objetivos, das estratégias na avaliação do input, das reações na avaliação, que focam no implemento das 
melhorias, e a avaliação do resultado avalia. A combinação destes modelos possibilita mensurar a eficácia dos Programas. Sendo assim, o modelo criado mensura a mudança de comportamento (proposta pelo modelo de Kirkpatrick) e não contemplada por CIRO, ao mesmo tempo que abrange a mensuração do Programa antes do treinamento de variáveis, como objetivos, conteúdo e recursos necessários (proposta pelo modelo de CIRO) não contemplado pelo modelo de Kirkpatrick (1979).

O modelo Integrated Model of Training Evaluation and Effectiveness, elaborado por Alvarez, Salas e Garofano (2004) inicia-se com a análise das necessidades do Programa. Esta análise está fortemente associada às áreas de conteúdo e design do treinamento, às mudanças associadas à aprendizagem e aos retornos organizacionais.

O Modelo IMPACT - Modelo Integrado de Avaliação do Impacto do Treinamento no Trabalho mensura o impacto em amplitude do treinamento no ambiente de trabalho. Este modelo considera a avaliação dos resultados da aplicação de um treinamento específico aplicados pelo treinado, efetivamente, em seu trabalho, por meio de sete componentes: suporte organizacional, características do treinamento, características da clientela, reações, aprendizagem, suporte à transferência e impacto do treinamento no trabalho (Carvalho \& Abbad, 2006; Coelho Junior \& Abbad, 2010; Dias \& Guimarães, 2016).

O modelo Four-phase Evaluation System, elaborado por Lingham, Richley e Rezania (2006), apresenta fases para a avaliação do Programa: desenvolve-se a estrutura do Programa com foco nos objetivos organizacionais; a seguir, inicia-se a segunda fase para verificar quão bem o Programa está sendo executado; e, na sequência, explora-se a percepção dos participantes a respeito do Programa com foco no conteúdo, na aplicabilidade e no resultado do treinamento.

O Framework for Summative Evaluation Phase Within Systematic Training foi desenvolvido por Wang e Wilcox (2006) baseado no modelo de Kirkpatrick (1979). Nesse Framework a fase de avaliação do Programa é sintetizada na pós-aprendizagem. Com isso o valor da aprendizagem ou avaliação do Programa é formado pela avaliação a curto prazo, formada pelo resultado das medidas de reação e aprendizagem dos colaboradores mais a avaliação a longo prazo de seus comportamentos no trabalho do aluno.

As áreas baseiam-se em seis medidas de avaliação propostas pelos estudos de Kirkpatrick (1976), de Holton (1996) e de Tannenbaum et al. (1993), sendo elas: reações, atitudes pós-treino eficazes, aprendizagens cognitivas, desempenho do treinamento, transferência de desempenho e resultados provenientes de características dos indivíduos ou da organização.

Os modelos lógicos visam à quantificação dos elementos que os compõem, pois orientam o processo de construção do modelo de avaliação a ser utilizado, sobretudo na acepção dos resultados organizacionais do programa e das variáveis contextuais capazes de afetá-los (Meneses \& Abbad, 2009). Este modelo junto com a MCDA-C e IMPACT utilizam-se de fatores contextuais. Porém, o MCDA-C possui no final do modelo as ações de recomendações.

O modelo Multicritério de Apoio à Decisão Analytical Hierarchy Process foi desenvolvido por Saaty (1980). Esse modelo foi proposto para resolução de problemas complexos no qual se decompõe o problema em subproblemas por meio de uma estrutura hierárquica, segundo o julgamento do decisor (Suliyanto \& Setyawati, 2015; Lucas et al., 2017). Destaca-se que esse método converte o julgamento em pesos de forma direta, sem passar a avaliação dos pesos por um processo psicofísico. Também se observa que, ao alocar uma nova alternativa, se prejudica a condição de independência do modelo.

$\mathrm{Na}$ avaliação feita por Jeschke et al. (2017), eles utilizaram para mensurar a avaliação, tanto formativa como somativa, de processos fornecidos por Saunders, Evans e Joshi (2005). Para Saunders, Evans e Joshi (2005), a avaliação de processos foca variáveis como recrutamento, alcance, dose-delivered, dose-received, fidelidade, satisfação e contexto para mensurar o impacto (Jeschke et al., 2017). Na avaliação feita por Jeschke et al. (2017), a 
mensuração do Programa apenas se concentrou nas atividades de intervenção e saída com enfoque em resultados de impacto a curto e médio prazos.

A avaliação Success Case Method, proposta por Lee et al. (2017), considera que os efeitos do treinamento são funções da interação do treinamento com outros elementos do Sistema de Desempenho da Avaliação de Programas. A Success Case Method, no primeiro momento, questiona os participantes do Programa a responder se o treinamento teve algum impacto em seu desempenho no cargo. A seguir, identificam-se os grupos bem e malsucedidos e a análise em profundidade de resultados do treinamento para entender as deficiências e necessidades de melhoria do Programa.

\section{PROCEDIMENTOS METODOLÓGICOS}

\subsection{ENQUADRAMENTO METODOLÓGICO}

Em relação à natureza dos objetivos, esta pesquisa classifica-se como descritiva (Sampieri, Collado, \& Lucio, 2013) porque busca conhecer o contexto em que a DEAP está inserida e gerar conhecimento para a diretora da Instituição quanto aos aspectos a serem considerados e gerenciados nos Programas de Treinamento oferecidos pela DEAP.

Quanto à abordagem, enquadra-se como qualitativa (Sampieri, Collado, \& Lucio, 2013), pois, na Fase da Estruturação do modelo, se conhece o contexto da DEAP para identificar os aspectos em que o desempenho será mensurado e gerido.

$\mathrm{Na}$ Fase da Recomendação, apresentam-se as propostas para melhoria contínua do Programa de Treinamento naqueles descritores (escalas ordinais) nos quais o Programa apresentou desempenho comprometedor. Para assegurar a confiabilidade qualitativa, houve a preocupação em descrever e entender o contexto da DEAP na etapa da Contextualização, pertencente à Fase de Estruturação (metodologia MCDA-C), e apresentar de forma detalhada os procedimentos metodológicos.

Acredita-se que com os procedimentos metodológicos expressos, minimiza-se as ameaças a confiabilidade qualitativa, ou seja, os processos de coleta fizeram com que as crenças das próprias pesquisadoras não interferissem na coerência e sistematização das interpretações dos dados (Sampieri, Collado, \& Lucio, 2013). Assim, a confiabilidade qualitativa está presente na possível constatação por outros pesquisadores sobre a sistematização na coleta e análise qualitativa. Logo, ao se delinearem os procedimentos, outros pesquisadores podem replicar a pesquisa.

Quanto à credibilidade, as pesquisadoras estabeleceram um Código de Conduta, com base nas recomendações coletadas em Sampieri, Collado, e Lucio (2013), seguido durante toda a pesquisa, qual seja: (a) respeitar os valores, opiniões e percepções dos decisores; (b) assegurar que os valores, opiniões e percepções não influenciem o papel das pesquisadoras; (c) ouvir igualmente os dois decisores envolvidos nesta pesquisa; (d) apresentar, sempre que possível, evidência de argumentos a favor e contra; (e) se as pesquisadoras estivessem convencidas de um conflito de interesse, deveriam deixar clara a existência do conflito e expressamente declarada a todas as partes interessadas nessas decisões; (f) disponibilizar para um membro externo, expert na metodologia MCDA-C, os dados e as análises feitos para uma avaliação externa do andamento da pesquisa; (g) documentar de forma precisa os dados e informações coletados, os procedimentos realizados e os resultados parciais obtidos no curso desta pesquisa; e, (h) preservar adequadamente os dados e informações obtidos.

No caso de ocorrência de conflito de interesse entre os decisores durante a entrevista, citam-se as estratégias que foram utilizadas: (a) se algum decisor discordar, entre eles, do Elementos Primários de Avaliação (EPA), solicitar justificativa e, conforme ela sugerir, manter devido à etapa de expansão desses EPAs em conceitos; (b) se algum decisor discordar, entre 
eles, do Conceito, solicitar justificativa e, conforme ela sugerir, criar outro EPA ou Conceito; (c) se algum decisor discordar, entre eles, do Família de Pontos de Vista (FPV), solicitar justificativa e, conforme ela sugerir, criar outro FPV ou reformular esse FPV; e, (d) se algum decisor discordar, entre eles, do Mapa Cognitivo, solicitar justificativa e, conforme ela rever, a possibilidade de criar mais EPAs, Conceitos e FPV. Esses protocolos preservaram e auxiliaram na comunicação entre pesquisadoras e decisores. A confirmação se estabeleceu quando as pesquisadoras validaram e legitimaram cada etapa do modelo com os decisores, sendo esse critério vinculado ao critério da credibilidade. A checagem com os decisores auxiliou na confirmação de que a informação prestada era fidedigna e relevante para o contexto (Sampieri, Collado, \& Lucio, 2013).

Quanto à aplicabilidade dos resultados, em um estudo qualitativo não se busca a generalização, entretanto a essência de seu resultado pode oferecer possíveis caminhos ou ideias de formulação para outros estudos em contextos diferentes (Sampieri, Collado, \& Lucio, 2013). Para auxiliar a possibilidade de transferência, os resultados descrevem o contexto da DEAP, os decisores e processos de coleta para a estruturação do modelo e evidenciam, de forma clara, a análise dos resultados e a conclusão desta pesquisa. Cumpre observar que, segundo Sampieri, Collado e Lucio (2013), a possibilidade de transferência não poderá ser total devido à incapacidade de existirem contextos iguais.

A coleta de dados foi realizada por meio de dados primários (Richardson, 1999). Referem-se a dados primários os coletados in loco por meio de entrevistas semiestruturadas com a diretora (gestora) da DEAP e com o administrador da SEA, visando à percepção dos decisores sobre as particularidades do contexto e os objetivos almejados por ela quanto à avaliação de desempenho para, consequentemente, apoiar a gestão.

Em um primeiro momento, as pesquisadoras precisaram obter informações divulgadas no Portal do Servidor, no site da SEA-SC e da DEAPVirtual e notícias online sobre o contexto - Programa de Treinamento da DEAP - para entender a dinâmica do Programa e, assim, preparar perguntas essenciais e tempestivas. Isso possibilitou uma imersão inicial. Após essa imersão, estabeleceram-se 29 perguntas. As entrevistas foram gravadas no celular e armazenadas em HD externo.

Para os procedimentos técnicos, esta pesquisa se classifica como um estudo de caso ao construir um modelo de avaliação de desempenho personalizado com base na expansão de conhecimento de uma realidade específica: Programas de Treinamento oferecidos pela DEAP. Além de ser classificada como pesquisa bibliográfica pelo uso do ProKnow-C.

Como instrumentos de intervenção, esta pesquisa utilizou o Knowledge Development Process-Constructivist (ProKnow-C) e a metodologia Multicritério de Apoio à DecisãoConstrutivista (MCDA-C), apoiados pela epistemologia Construtivista. O ProKnow-C é um processo estruturado e sistemático para seleção e revisão crítica da literatura que promove a geração de conhecimento em relação ao tema (Ensslin, Ensslin, Imlau, \& Chaves, 2014; Hillen, Laffin, \& Ensslin, 2018). A metodologia MCDA-C tem como intuito a construção de um modelo de avaliação resultante da construção de conhecimento gerado no decisor (Ensslin, Dutra, \& Ensslin, 2000; Ensslin, Amaral, Valmorbida, \& Dutra, 2018).

\subsection{PROCESSOS PARA SELEÇÃO DOS ARTIGOS PARA O REFERENCIAL TEÓRICO}

Para seleção dos artigos que abordam a Avaliação de Desempenho de Programas de Treinamento e com base neles fundamentar o estudo, operacionalizou-se a primeira etapa pelo Knowledge Development Process-Constructivist (ProKnow-C), conforme ilustrado na Figura 2 (Ensslin et al., 2018; Hillen, Laffin, \& Ensslin, 2018). 


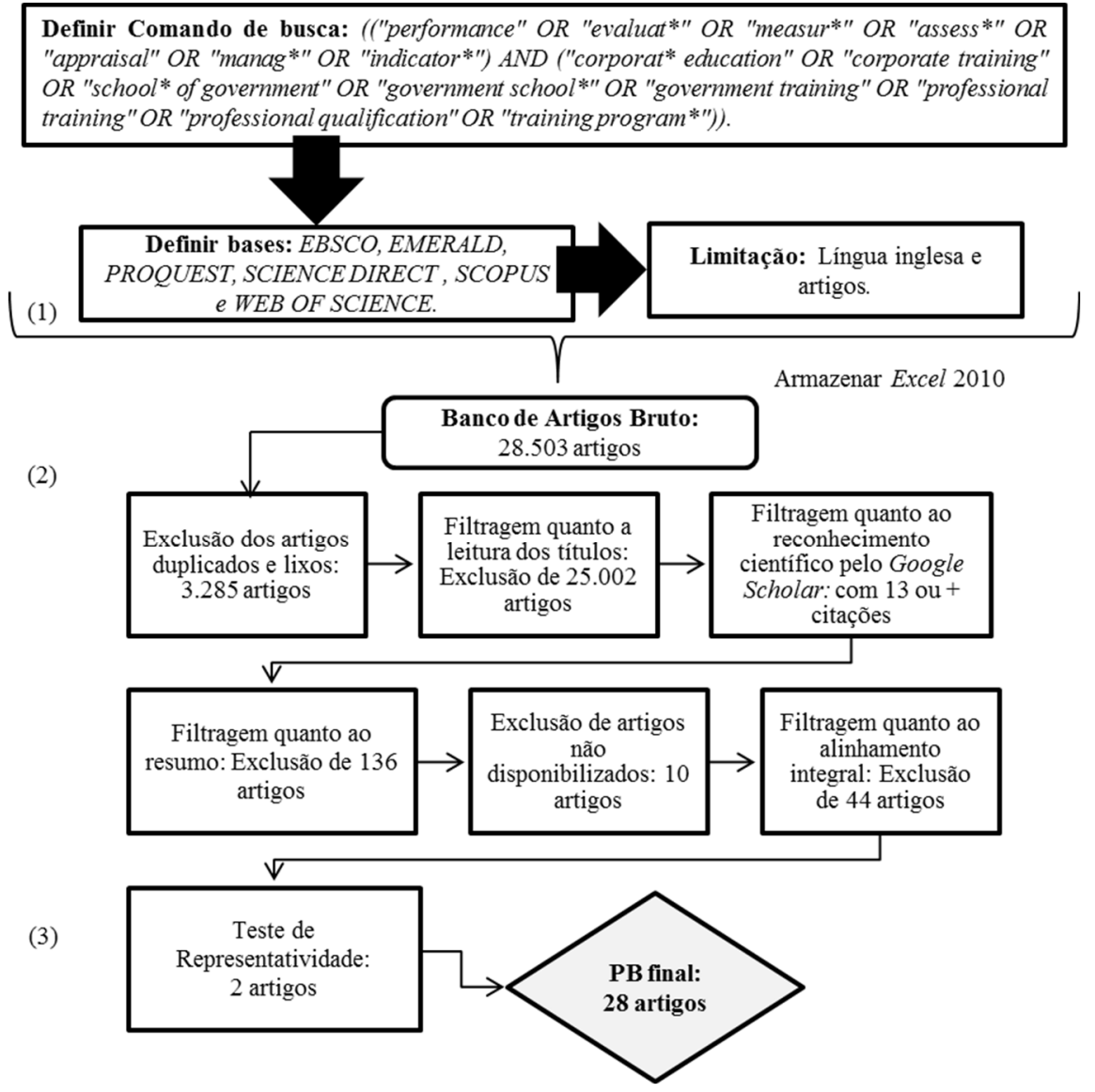

Figura 2. Processo de seleção dos artigos Fonte: Dados da pesquisa.

A estrutura do ProKnow-C é composta por quatro etapas: (i) Seleção de Portfólio Bibliográfico (PB); (ii) Análise Bibliométrica; (iii) Análise Sistêmica; e (iv) Formulação de Perguntas e Objetivos de Pesquisa (Ensslin, Ensslin, Imlau, \& Chaves, 2014; Hillen, Laffin, \& Ensslin, 2018). A operacionalização da etapa de Seleção do PB envolveu a seleção do Banco de Artigos Bruto; a Filtragem do Banco de Artigos; e o Teste de Representatividade.

\subsection{INSTRUMENTO DE INTERVENÇÃO DE CONSTRUÇÃO DO MODELO: MULTICRITÉRIO DE APOIO À DECISÃO-CONSTRUTIVISTA (MCDA-C)}

Com o objetivo de auxiliar os gestores organizacionais na resolução de seus conflitos, surgiram, em meados do século XX, as Metodologias Multicritérios na Pesquisa Operacional. A Pesquisa Operacional, desenvolvida por pesquisadores matemáticos em plena Segunda Guerra Mundial, segregou-se em duas vertentes: Pesquisa Operacional Soft e Pesquisa Operacional Hard (Ensslin, Dutra, \& Ensslin, 2000).

A Pesquisa Operacional Soft analisa a estruturação do contexto decisório buscando o apoio à decisão, adotando uma visão prescritivista e, mais tarde, construtivista que deu origem à metodologia Multicriteria Decision Aid (MCDA) no contexto internacional (Roy, 1993) e, posteriormente, no contexto nacional, à Multicritério de Apoio à Decisão-Construtivista (MCDA-C) (Ensslin, Dutra, \& Ensslin, 2000; Tasca, Ensslin, \& Ensslin, 2012).

A metodologia MCDA-C vai na direção da geração de conhecimento daqueles que necessitam de informações, materializadas em um modelo, para apoiar suas decisões. Nessa perspectiva, assume-se que os indivíduos (organização) não possuem pleno conhecimento sobre os objetivos, com base em suas percepções e valores, a serem considerados no modelo de 
avaliação (Ensslin, Dutra, \& Ensslin, 2000, Tasca, Ensslin, \& Ensslin, 2012, Bortoluzzi, Silva, \& Ensslin; Ensslin et al., 2013). Assim, a metodologia MCDA-C considera os envolvidos e seus valores, bem como as características dos objetivos e os elementos estruturais no contexto decisório. Além de proporcionar a geração de conhecimento e aprendizagem no decisor, este pode ser encontrado em contextos complexos, conflituosos e incertos, podendo intervir no desenvolvimento das três Fases recursivas - Estruturação, Avaliação e Recomendações - que resultarão na obtenção do modelo Multicritério Construtivista (Ensslin, Dutra, \& Ensslin, 2000, Tasca, Ensslin, \& Ensslin, 2012, Bortoluzzi et al., 2013).

Em geral, a Fase de Estruturação procura identificar e evidenciar os objetivos necessários para avaliar o contexto e suas escalas ordinais (descritores) de mensuração (indicadores), segundo os decisores. Na Fase de Avaliação, há a transformação dessas escalas ordinais em escalas cardinais e se identifica a contribuição de cada indicador no modelo global, propiciando a avaliação matemática global do desempenho. Como última fase, há a Fase de Recomendação, que sugere contribuição de ações focadas no aperfeiçoamento do desempenho. Esta pesquisa irá pormenorizar somente a Fase de Estruturação e a Fase de Recomendação (Ensslin et al., 2018).

A Fase de Estruturação dividiu-se em três etapas: Contextualização, Árvore de Pontos de Vista e Construção dos Descritores. A Contextualização é concebida pelas seguintes etapas: (i) caracterização do Ambiente; (ii) deliberação dos Atores; e (iii) apresentação do Problema. A Árvore de Pontos de Vista é integrada pelas etapas: (i) identificação dos Elementos Primários de Avaliação; (ii) construção dos Conceitos; e (iii) composição da Família de Pontos de Vista. E a Construção dos Descritores é composta por: (i) elaboração dos Mapas Cognitivos; (ii) Estruturação dos Mapas Cognitivos em Cluster e Subcluster; (iii) constituição da Estrutura Hierárquica de Valor; e (iv) desenvolvimento das Escalas Ordinais (Ensslin et al., 2018).

\subsection{CONGRUÊNCIA ENTRE OS INSTRUMENTOS DE INTERVENÇÃO}

Esta pesquisa utilizou, como instrumentos de intervenção o ProKnow-C e a metodologia MCDA-C. A execução integrada desses instrumentos facilita a interação entre as pesquisadoras e os decisores. A Figura 3 ilustra tal integração na Fase de Estruturação. 


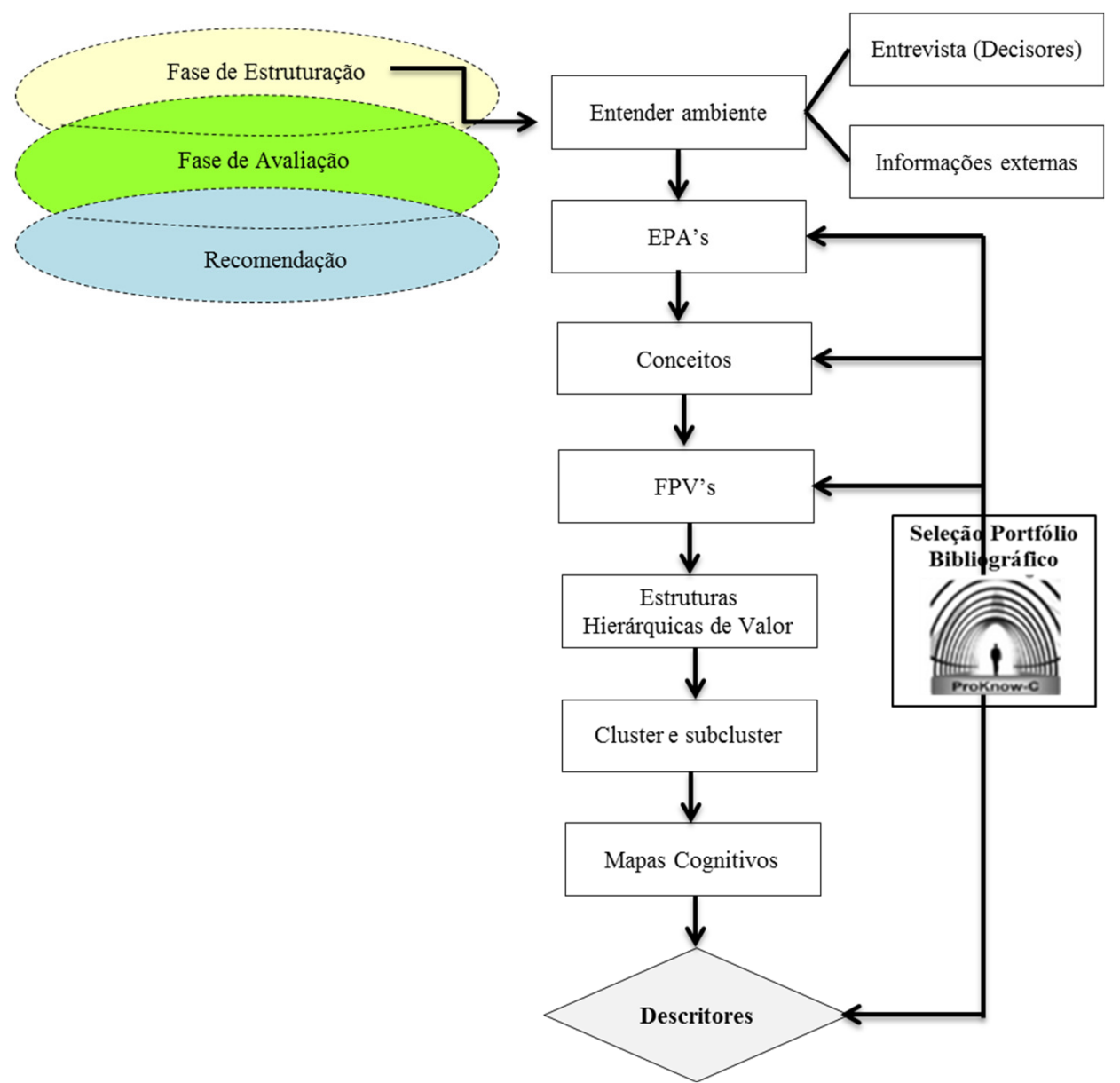

Figura 3. Interação do ProKnow-C na Fase da Estruturação da metodologia MCDA-C Fonte: Elaborada pelas autoras.

O ProKnow-C, além de proporcionar a sustentação teórica na pesquisa e possível identificação de lacunas, promoveu às pesquisadoras do modelo exercerem uma imersão inicial na 'perspectiva científica' da Avaliação de Programas de Treinamento. Essa imersão inicial dada pela execução do ProKnow-C permitiu às pesquisadoras, antes da realização das entrevistas com os decisores, conhecer neste primeiro momento o que seria, para quê e para quais contextos foram feitos a Avaliação de Desempenho de Programas de Treinamento na ciência. Desse modo, na reunião com os decisores, as pesquisadoras tinham conhecimento científico geral da avaliação dos Programas, o que facilitou o desenvolvimento de perguntas que levaram a conhecer o contexto específico da DEAP para a estruturação do ambiente.

Com o objetivo de conhecer o ambiente da DEAP, a utilização da metodologia MCDA$\mathrm{C}$ procurou identificar, com os decisores, suas preocupações e objetivos. Nesse momento, as informações capturadas no ProKnow- $C$ auxiliam as pesquisadoras a sugerir e expandir, quando adequado para a DEAP, outras preocupações e objetivos já utilizados em outras ferramentas. Essa integração com a literatura expandiu a compreensão dos decisores sobre seu contexto. Depois de se estabelecerem, na metodologia, os EPAs e constituir os FPVs, houve o processo de representação gráfica dessas etapas em forma de mapas cognitivos e estruturas hierárquicas de valor. Nesse momento, o ProKnow- $C$ não tem reflexo direto nas pesquisadoras. Em seguida, há a constituição dos descritores. Nesse momento, a revisão da literatura pode contribuir ao fornecer possíveis adaptações para a mensuração dos objetivos delimitados pela DEAP. 


\section{ANÁLISE E DISCUSSÃO DOS RESULTADOS}

Esta seção explicita o desenvolvimento do modelo destinado a subsidiar Avaliação de Desempenho do Programa de Treinamento, fornecido pela DEAP aos servidores públicos.

\subsection{FASE DA ESTRUTURAÇÃO}

\subsubsection{Contextualização ou abordagens soft para estruturação}

No contexto da metodologia MCDA-C o problema é uma construção do modo como o decisor interpreta seu contexto decisório, isto é, existe a necessidade de identificar o problema com base na visão do decisor (Ensslin et al., 2018). Assim, essa etapa esclarece o contexto parcialmente conhecido, os atores envolvidos no problema, o rótulo e o sumário do trabalho.

O local objeto deste estudo é a DEAP, que é responsável pelo aperfeiçoamento profissional da SEA-SC, por meio da DEAPVirtual. A DEAP auxilia a SEA-SC a cumprir parte de sua missão na deliberação e gestão de políticas administrativas de Recursos Humanos, buscando melhoria dos serviços prestados à sociedade (Portal da SEA-SC, 2018). Em vista disso, a SEA-SC e a DEAP visualizam o treinamento para aprimoramento dos servidores públicos como meio de formação do perfil profissional demandado pelo setor público.

Em conformidade com a missão da SEA-SC, a DEAP, juntamente com a DEAPVirtual, preza em desenvolver as competências dos servidores públicos estaduais para promover a excelência profissional e organizacional em seus serviços à sociedade catarinense (Portal da SEA-SC, 2018). A DEAPVirtual foi desenvolvida, em Santa Catarina, pela Lei Complementar n. 381, de 7 de maio de 2007, sendo suas atribuições dispostas pela Lei Complementar n. 16.480, de 28 de outubro de 2014, e pelo Decreto n. 628, de 2 de março de 2016 (Portal do Servidor, 2018).

A DEAPVirtual abrange uma estrutura on-line de Educação a Distância devido à economicidade, maior cobertura de público-alvo e praticidade. Essa Escola Virtual dispõe de atividades baseadas em cursos/trilhas de aprendizagens, eventos virtuais, web conferências, videoconferências e reuniões virtuais (Portal do Servidor, 2018). Para desenvolver essas atividades, utiliza, como ferramentas tecnológicas de Educação a Distância, Ambiente virtual de aprendizagem, TV Corporativa e Adobe Connect (Portal DEAPVirtual, 2018).

Nesta pesquisa, os decisores priorizaram analisar o problema vivenciado no contexto do ambiente virtual de aprendizagem, executado pelo software livre Modular Object-Oriented Dynamic Learning Environment (Moodle). Esse software livre é utilizado para operacionalizar os cursos e trilhas de aprendizagem com interesses gerais, sistêmicos e finalísticos de maneira personalizada, visando atender às peculiaridades do treinamento estadual (Portal do Servidor, 2018). No momento, o Moodle contém 22 cursos gratuitos ofertados aos servidores, funcionários, empregados públicos, estagiários e prestadores de serviço pertencentes aos órgãos, entidades e instituições públicas, estaduais, municipais e dos Poderes do Estado de Santa Catarina (Portal do Servidor, 2018).

Diante deste contexto, os atores envolvidos no processo de educação a distância são a Diretora da Escola de Administração Pública e um administrador da SEA-SC, no papel dos decisores. Tem-se ainda, o Secretário Adjunto, o Secretário de Administração e o Diretor de Gestão e Desenvolvimento de Pessoas como intervenientes; as autoras da pesquisa atuando como facilitadoras; e Servidores que realizam os cursos disponibilizados no Moodle e População em geral impactada pelas consequências do atendimento dispensado pelos servidores envolvidos nos cursos de capacitação no papel de agidos.

O problema encontrado pelos decisores neste contexto foi a ausência de um modelo de desempenho que apoie a gestão interna da DEAP em seu programa de capacitação, a fim de respaldar o contexto de decisão, bem como monitorar o desempenho, evidenciar os resultados gerados e recomendar ações de melhorias. 


\subsection{2 Árvore de pontos de vista}

Essa etapa iniciou-se com a identificação dos Elementos Primários de Avaliação (EPAs), definidos como preocupações iniciais dos decisores que acabam interferindo em suas percepções sobre o processo decisório (Costa, 1992). Com base nas entrevistas e na técnica de brainstorming, constataram-se 38 EPAs. Observa-se que os EPAs são informações iniciais acerca do problema, logo há a necessidade de expandir o entendimento sobre cada EPA. Essa expansão de conhecimento denomina-se Conceitos, os quais são orientados pela ação.

Os Conceitos são construídos sob a percepção dos decisores, os quais evidenciam o desempenho pretendido (Polo Presente) e o desempenho mínimo que o decisor deseja evitar (Polo Oposto psicológico) (Ensslin et al., 2018). Desse modo, foram construídos 60 conceitos mediante os desmembramentos dos EPAs.

A Tabela 2 apresenta parte dos EPAs e dos seus Conceitos construídos. A coluna dos números é apenas para marcar a criação de conceitos de forma didática. No início foram marcados 1 ao 39 na primeira etapa da entrevista. Depois da primeira entrevista os decisores solicitaram acrescentar outros conceitos que foram criados a partir do numeral 100 para mostrar a recursividade do modelo. Ao contar cada número na Figura 4, tem-se os 60 conceitos.

Ressalta-se que o Polo Oposto psicológico é representado pelas reticências (...) e deve ser lido "ao invés de".

Tabela 2. Exemplos EPAs e Conceitos

\begin{tabular}{|l|c|l|l|l|}
\hline $\begin{array}{c}\text { Elemento Primário de } \\
\text { Avaliação }\end{array}$ & $\mathbf{N}^{\mathbf{o}}$ & \multicolumn{1}{|c|}{ Polo presente } & (...) & \multicolumn{1}{|c|}{ Polo psicológico oposto } \\
\hline Satisfação & 1 & $\begin{array}{l}\text { Garantir a satisfação no processo } \\
\text { de capacitação via ambiente } \\
\text { Moodle }\end{array}$ & $(\ldots)$ & $\begin{array}{l}\text { Perder servidores por } \\
\text { insatisfação do curso }\end{array}$ \\
\hline Gestão & 119 & $\begin{array}{l}\text { Garantir proatividade na gestão } \\
\text { interna }\end{array}$ & $(\ldots)$ & $\begin{array}{l}\text { Inviabilizar a realização dos } \\
\text { cursos }\end{array}$ \\
\hline Limitação de acesso & 120 & $\begin{array}{l}\text { Disponibilizar acesso aos cursos } \\
\text { para outros órgãos públicos e } \\
\text { organizações privadas }\end{array}$ & $(\ldots)$ & $\begin{array}{l}\text { Ter impedimento financeiro ou } \\
\text { tecnológico que impeça o } \\
\text { acesso }\end{array}$ \\
\hline
\end{tabular}

Fonte: Dados da pesquisa.

Com a composição dos Conceitos orientados à ação, segundo a ótica dos decisores, foi possível agrupá-los em grandes áreas de preocupação. Essas grandes áreas de preocupação são denominadas de Família de Pontos de Vista (FPV) ou up down (Costa, 1992). Após a constituição da FPV (Figura 4), testou-se a necessidade e suficiência de todos os Pontos de Vista Fundamentais.

$\mathrm{Na}$ Figura 4, observa-se que cada um dos 60 Conceitos foi vinculado a uma FPV. A criação destas FPV surgiu das preocupações/necessidades dos decisores. Essas preocupações puderam ser agrupadas em Gestão da Evasão, Temas do Curso, Criar Parcerias e Gestão Interna. 


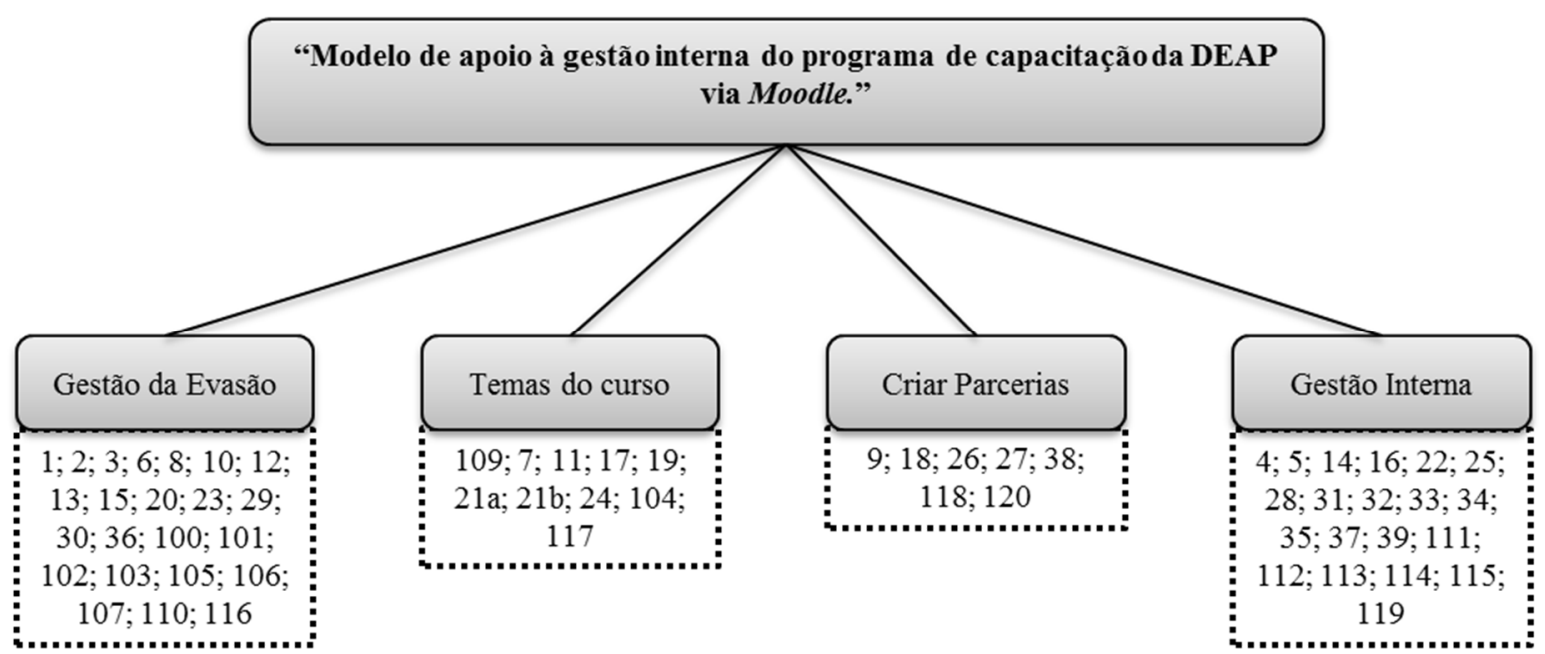

Figura 4. Família de Pontos de vista e teste quanto à necessidade e suficiência

Fonte: Dados da pesquisa.

A Primeira FPV formada, Gestão da Evasão, provém da seguinte fala do Decisor A ao comentar, no início da entrevista, as particularidades dos cursos à distância ofertados:

[...] Na realidade, a Educação a Distância tem por si só um percentual de desistência. Digamos assim: Não tem uma abrangência como a educação presencial. A média de desistência (de não conclusão) da Educação a Distância é uma média grande comparada com a presencial. Já é uma média de $15 \%$ a $20 \%, 10 \%$ a $20 \%$. Isso seja graduação ou curso de educação continuada. O que eu acredito é que a metodologia com que a pesquisadora irá trabalhar que ela seja justificada e apresentada. É que a gente possa trabalhar, por exemplo, a sazonalidade neste período [...] o porquê isso está ocorrendo no Estado [...]. Por que há essa desistência? Se o problema é o curso? O problema é tempo? O que o Estado pode fazer para melhorar, adequar essa desistência, diminuir essa desistência [...] Entender o porquê disso [...] (DECISOR A, 2018).

Em seguida, a FPV de Temas do curso pode ser identificada quando os decisores buscavam entender o processo de evasão e associavam a possibilidade do tema, mas depois entraram num consenso que os temas dos cursos fazem parte de uma preocupação maior com objetivos diferentes da Evasão. Fala do Decisor A:

Outro interessante que eu gosto muito. É que tem cursos que são extremamente visados pelos alunos, e outros não. Aí assim, eu não sei se é porque os alunos, o tema é bom ou se o curso é ruim mesmo e ninguém não quer fazer. Aí poderíamos ter algo que nos fizesse entender se o curso é ruim, se o tema é ruim. [...] Interesse dos alunos. (DECISOR A, 2018)

Depois, os decisores comentaram sobre a necessidade desses temas para o Estado e para os servidores e se os temas estão atualizados. Para o Decisor A, é necessário esse feedback dos servidores e da Chefia Imediata, a fim de identificar cursos que precisem de alguma revisão por estarem desatualizados ou que não estejam atendendo à aplicabilidade dos servidores e do Estado.

A Terceira FPV, Criar Parcerias, instituiu-se pela fala do Decisor B: "Porque a sinalização de temas de interesse permitiria a postura de buscar parcerias. Vamos buscar lançar um curso nesse tema, naquele tema, né? E parcerias até com outras escolas virtuais, ENAP e FGV".

Para o Decisor A (2018), "quando falo parcerias penso em Conselhos. Em Administração Pública seja ela municipal, estadual e federal.” Também com rede de ensino 
público, principalmente nas Escolas de Governo que, segundo o Decisor A (2018), esses meios atualizam esses conteúdos conceituando parcerias como "[...] Compartilhamento, Cooperação. [...] Trocas de cursos". O Decisor B (2018) complementa que "essa parceria é no acesso a conteúdo, já prontos em termos de cursos. Na oferta de outros produtos".

Durante a entrevista, entende-se pela fala dos decisores que a cooperação, e não a competividade, é uma alternativa a ser aplicada pelos servidores na falta de recursos públicos.

Por fim, a FPV Gestão Interna constituiu-se pelas seguintes falas dos decisores: "Agora preciso gerir esse ambiente" (Decisor A, 2018). "Modelo de Avaliação de Desempenho da gestão do ambiente de aprendizagem Moodle para apoiar a gestão da escola" (Decisor B, 2018). "Todos os relatórios podem ser tirados do sistema, mas não tenho tempo pra isso" (Decisor B, 2018). A partir dessas falas, os facilitadores perceberam a ausência de um processo de coleta de dados, que busque evidenciar o porquê, para que e como sua gestão, para assim administrar sua equipe e respaldar suas decisões.

Após a constituição de todos os Pontos de Vista Fundamentais pelos decisores procedese à etapa de Construção dos descritores.

\subsubsection{Construção dos descritores}

Nesta etapa, a construção dos descritores subsidiou os decisores a compreender quais informações são necessárias e como coletá-las para evidenciar os níveis potenciais e comprometedores no Programa de Treinamento da DEAP. Isso permite à gestão da DEAP estabelecer e reestruturar metas e desenvolver ações de melhoria contínua para o funcionamento dos cursos.

Com a constituição dos Conceitos em quatro áreas gerenciáveis, iniciou-se a etapa de construção dos Descritores com a elaboração dos Mapas Cognitivos. A estruturação dos Mapas Cognitivos, ou Mapas de Relações de Meios-Fins, propicia aos decisores visualizar um panorama de seus objetivos. Esses Mapas Cognitivos interligam os Conceitos, alicerçados em suas relações de defluência entre meios e fins e objetivam, cada vez mais, expandir o entendimento do contexto vivenciado na DEAP por um conjunto de Pontos de Vista Fundamentais.

Para a construção dos Mapas Cognitivos, indagou-se aos decisores a respeito de como alcançar esse Conceito e para que se destina tal Conceito, posto que os Conceitos mais baixos representam os meios (funções táticas e operacionais) dos objetivos estratégicos representados pelos Conceitos mais acima. A Figura 5 ilustra o resultado desse processo com o Mapa Cognitivo da FPV de Gestão Interna.

Com base na composição dos Cluster e Subcluster, a metodologia MCDA-C decompõe seus Pontos de Vista Fundamentais em Pontos de Vista Elementares. Essa decomposição é designada como Estrutura Hierárquica de Valor (EHV). Essa estrutura evidencia os aspectos que os decisores levam em consideração na gestão do Programa de Treinamento na DEAP. De posse dos aspectos passa-se à construção dos descritores; ou seja, a escala ordinal para cada um desses aspectos do modelo.

Nesse momento das entrevistas, os decisores concordaram com Neely, Gregory e Platts (1995) ao não terem complicações em se identificar o que mensurar, mas, sim, em se preocuparam como e para que gerenciar os descritores. 


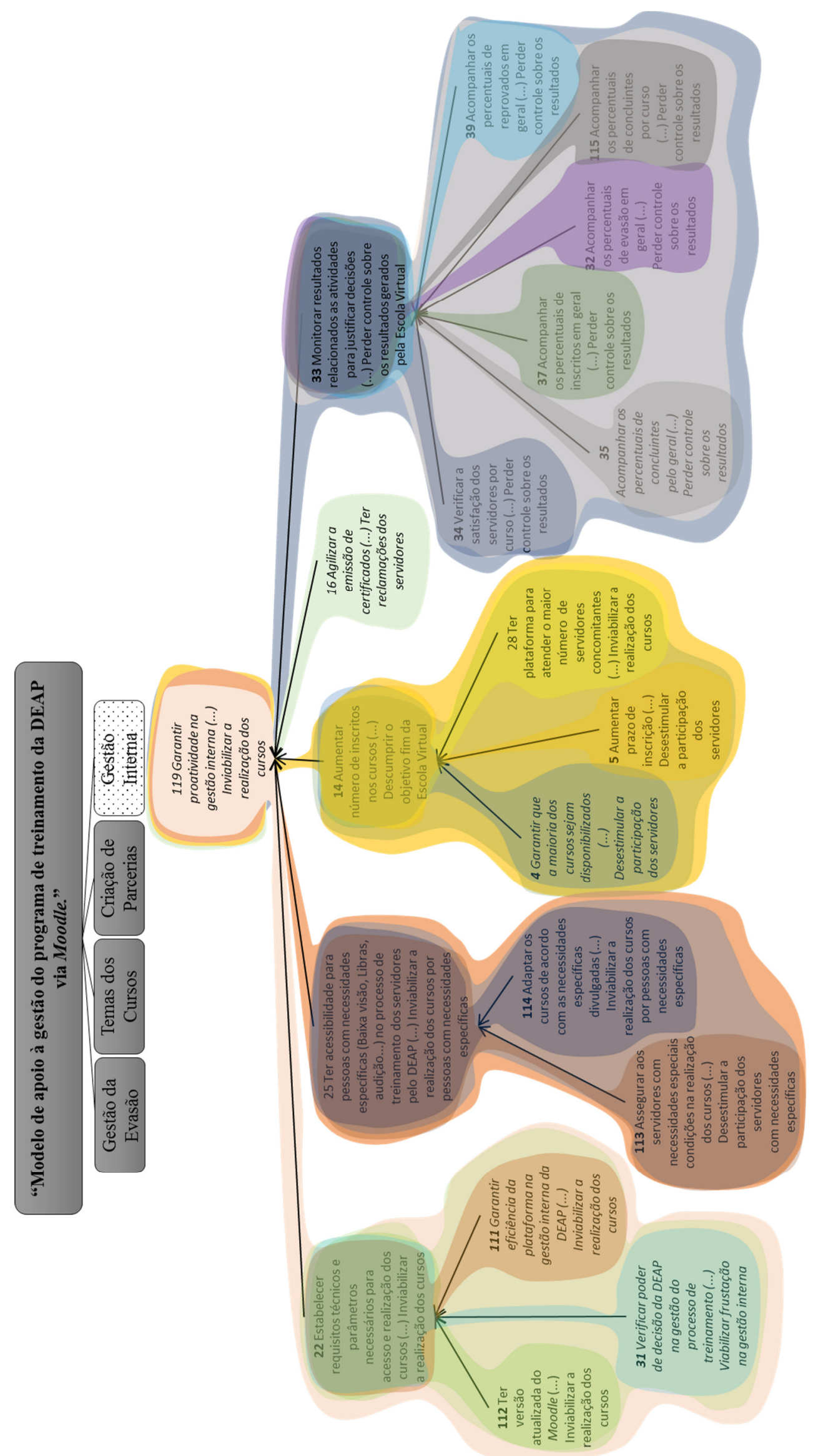

Figura 5. Mapa Cognitivo com Cluster e Subcluster do FPV de Gestão Interna Fonte: Dados da pesquisa. 


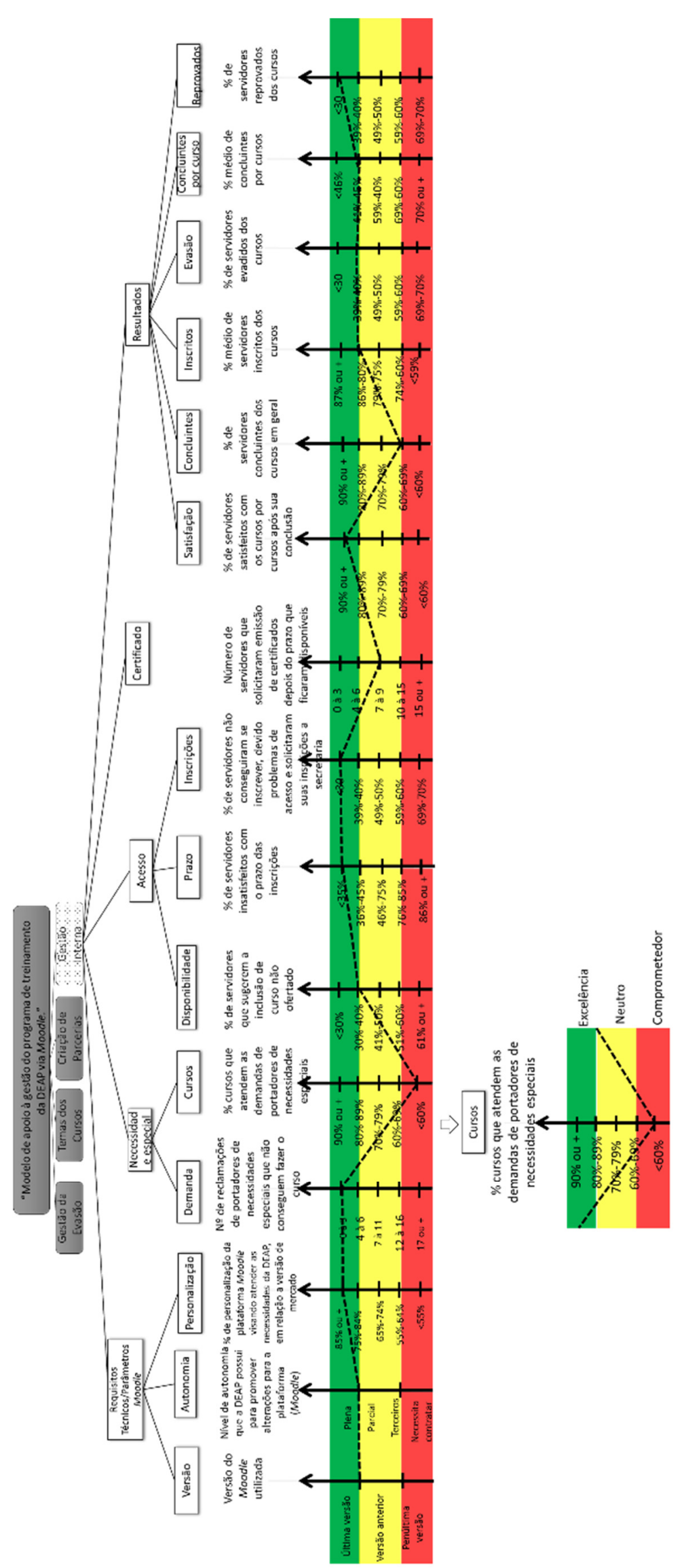

Figura 6. EHV e descritor do FPV de Gestão Interna Fonte: Dados da pesquisa. 
A mensuração na Fase da Estruturação deriva do desenvolvimento de escalas ordinais que traduzem as direções de preferências dos decisores. As escalas ordinais são compostas por níveis de impactos, os quais possuem níveis de ancoragem ou de referência. Com objetivo da construção dos descritores cometidos, onde eles tornam compreensíveis os Pontos de Vista sem criar ambiguidade na mensuração, pode-se obter o status quo do Programa de Treinamento da DEAP, via Moodle, conforme a Figura 6.

Após a construção dos descritores, deu-se por concluída a Fase de Estruturação e iniciou-se a Fase de Recomendações.

\subsection{FASE DE RECOMENDAÇÃO}

A Fase de Recomendações oportunizou aos decisores aprender como gerenciar seu status quo. Essa fase permitiu aos decisores construir ações de melhoria para os níveis de desempenho neutros ou comprometedores, possibilitando atingir os níveis de excelência. Esta característica diferencia o modelo aqui construído informado pela metodologia MCDA-C dos modelos que são gerados com base nas ferramentas apresentadas no Referencial Teórico. Por exemplo, a Tabela 3 apresenta ações de melhoria para o descritor evidenciado na Figura 6.

Tabela 3 - EPAs e Conceitos

\begin{tabular}{|l|l|}
\hline \multicolumn{1}{|l|}{ Descritor: \% cursos que atendem as demandas de portadores de necessidades especiais } \\
\hline \multirow{4}{*}{ Ações } & Verificar os tipos de necessidades especiais dos servidores. \\
\cline { 2 - 2 } & Constatar se os cursos ofertados no momento atendem estes servidores. \\
\cline { 2 - 2 } & Criação de cursos que atendam essas necessidades. \\
\cline { 2 - 2 } & Técnicos para a produção de material destes cursos. \\
\cline { 2 - 2 } & $\begin{array}{l}\text { Portal de sugestões no sistema para que sejam identificados possíveis } \\
\text { problemas. }\end{array}$ \\
\hline Recursos necessários & Pessoas e sistema Moodle. \\
\hline $\begin{array}{l}\text { Frequência do } \\
\text { acompanhamento }\end{array}$ & Contínuo. \\
\hline Responsável & Coordenação do Moodle. \\
\hline
\end{tabular}

Fonte: Dados da pesquisa.

\subsection{PERCEPÇÃO SOBRE ASPECTOS DA LITERATURA COM A PERCEPÇÃO DOS DECISORES}

Com a operacionalização da metodologia MCDA-C, os decisores da DEAP puderam construir conhecimento sobre seu contexto. Esta metodologia permitiu sanar a limitação do modelo de Kirkpatrick (1979) e seus derivados ao dar voz ao decisor. Desse modo, a participação do decisor na construção do processo de avaliação permitiu a ele impor seus objetivos no processo decisório.

O modelo de Kirkpatrick (1979) e seus derivados impõem os níveis de avaliação do programa, excluindo os fatores contextuais circundantes do programa de treinamento. Os decisores da DEAP entendem que suas necessidades sobrepõem tais níveis ou como chamado no modelo áreas de preocupação, sendo elas: a gestão da evasão, temas, criação de parcerias e gestão interna. Nos artigos do PB, o MCDA-C e o IMPACT consideram os fatores contextuais.

No entanto, dentro dessas áreas de preocupação identificadas pelos decisores pode-se verificar alguns descritores que correspondem ao nível de reação e aprendizagem de Kirkpatrick (1979). Mesmo os decisores da DEAP entendendo que o programa de treinamento é para atender a SEA-SC, necessita-se saber como o Programa é visto pelos servidores e quão bem os conhecimentos estão refletindo o dia-dia dos servidores. 
As ferramentas demonstradas na Tabela 1 estão ligadas, sobretudo a mensuração do nível de reação e aprendizagem. Posto que as informações coletadas para esses níveis são mais fáceis de se obter por depender da visão do aluno-colaborador.

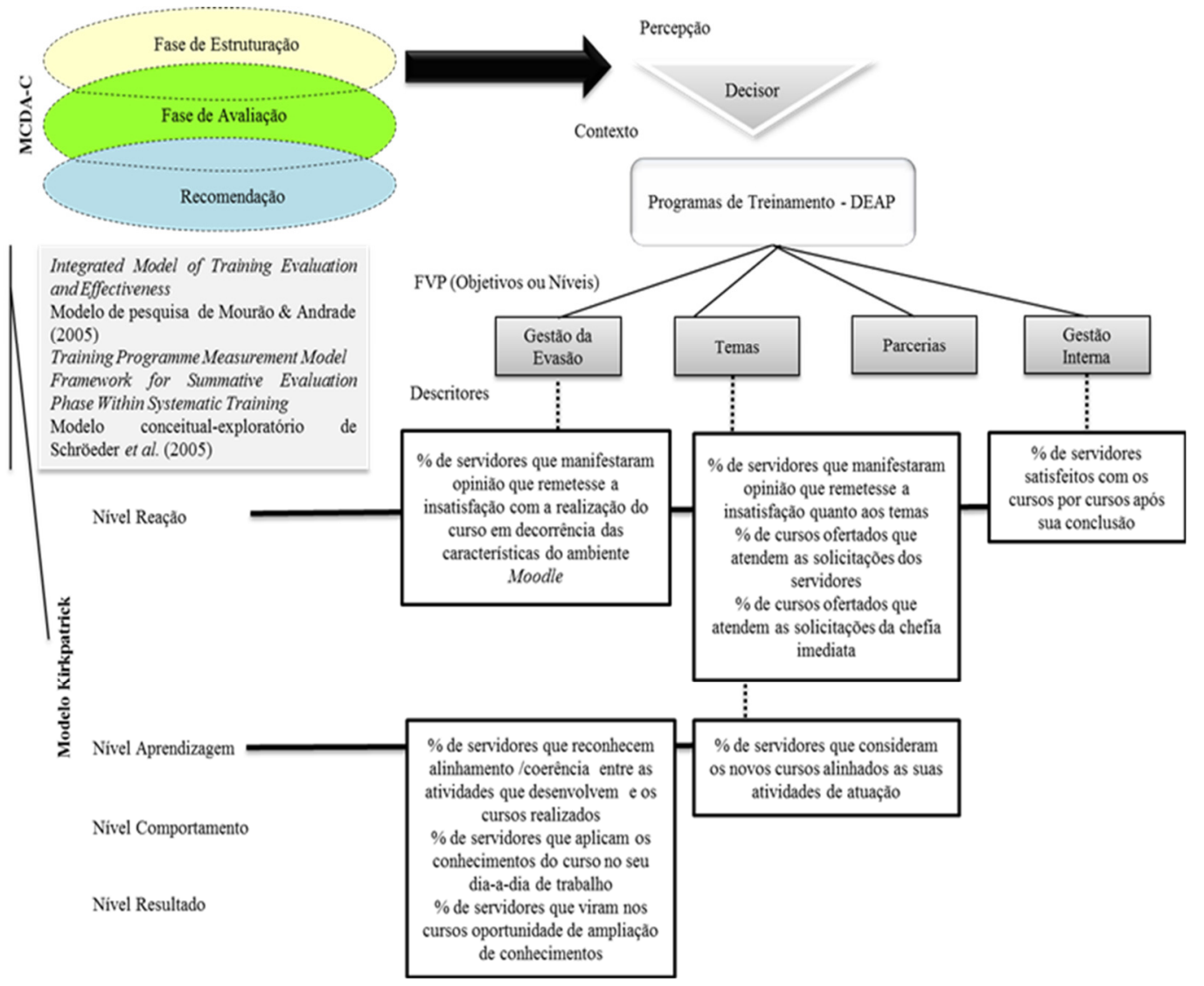

Figura 7. Percepção sobre aspectos da literatura com a percepção dos decisores Fonte: Dados da pesquisa.

Como pode-se observar na Figura 7, as necessidades dos decisores se sobressaem aos quatro níveis propostos por Kirkpatrick. Nesse sentido, o modelo MCDA-C não excluiu os fatores contextuais circundantes do Programa de Treinamento da DEAP.

\section{CONSIDERAÇÕES FINAIS}

Diante da importância dos Programas de Treinamento como suporte ao desenvolvimento da competência organizacional dos órgãos públicos e, por conseguinte, garantir que seus servidores apresentem desempenhos de qualidade, há a necessidade de se estabelecerem procedimentos avaliativos para o Programa de Treinamento.

Assim, esta pesquisa apresentou um modelo de Avaliação de Desempenho, focando uma abordagem epistemológica Construtivista para apoiar a Gestão do Programa de Treinamento, via Moodle, da Secretaria de Estado da Administração de Santa Catarina (SEA-SC), segundo as necessidades e percepções da gestora da DEAP. Para realizar esse objetivo, adotou-se os procedimentos metodológicos dos instrumentos ProKnow-C e da metodologia MCDA-C.

Com a operacionalização dos procedimentos e pressupostos da metodologia MCDA-C, nas entrevistas semiestruturadas com a gestora da DEAP e com o administrador da SEA-SC, foram identificados 38 EPAs, desmembrados em 60 conceitos. Esses conceitos foram 
agrupados em áreas de preocupação, sendo elas: Gestão da evasão; Temas dos cursos; Criação das parcerias; e Gestão interna.

Para avaliar o desempenho dessas áreas de preocupação que totalizaram todo o objetivo do Programa de Treinamento da DEAP e as necessidades dos decisores foram construídas 39 escalas ordinais (descritores). Dentre estes, observou-se que somente nove descritores (\% de servidores satisfeitos com os cursos por cursos após sua conclusão; \% de servidores que manifestaram opinião que remetesse a insatisfação quanto aos temas; \% de servidores que consideram os novos cursos alinhados as suas atividades de atuação; \% de cursos ofertados que atendem as solicitações dos servidores; \% de servidores que manifestaram opinião que remetesse a insatisfação com a realização do curso em decorrência das características do ambiente Moodle; \% de servidores que reconhecem alinhamento /coerência entre as atividades que desenvolvem e os cursos realizados; $\%$ de servidores que aplicam os conhecimentos do curso no seu dia-a-dia de trabalho; $\%$ de servidores que viram nos cursos oportunidade de ampliação de conhecimentos; \% de atividades governamentais contempladas pelos cursos ofertados (atividade meio)) se relacionam com os dois primeiros níveis de Kirkpatrick. Isso evidenciou que, mesmo esse modelo sendo o mais usual e conhecido nessa área, pode não representar as necessidades dos gestores e do Programa.

Cumpre observar que a existência de diferentes escalas ordinais (descritores) encontradas nos modelos publicados na literatura com as do modelo desta pesquisa justificamse pela metodologia MCDA-C atender às particularidades e características do Programa e a percepção dos decisores da DEAP durante cada etapa de construção do modelo. Outra justificativa identificada na literatura para essa diferença seria o alto custo relativo à constituição dos descritores sensíveis aos efeitos e objetivos do Programa (Sims, 1993; Mann \& Robertson, 1996).

Após o modelo qualitativo ter sido construído constatou-se que o Programa de Treinamento da DEAP apresentava alguns desempenhos comprometedores. Estes desempenhos foram estabelecidos pelos decisores. Ao identificar os desempenhos comprometedores, a metodologia MCDA-C admite não só avaliar o desempenho do Programa da DEAP, como também conduz à proposição de ações de aperfeiçoamento para o aprimoramento da qualidade do Programa e dos níveis de satisfação dos servidores envolvidos nos níveis abaixo da excelência.

Assim, as ações de aperfeiçoamento foram estabelecidas com base na capacidade da gestão da DEAP em executar a respeito da falta de recurso financeiro na SEA-SC, posto que o modelo foi criado para apoiar a gestão do Programa de Treinamento da DEAP, via Moodle. Cumpre salientar que em termos metodológicos esta pesquisa demonstrou a potencialidade dos dois instrumentos metodológicos utilizados para construção de conhecimento junto aos decisores e as pesquisadoras.

Como limitação central desta pesquisa tem-se o fato de que as ações de aperfeiçoamento, propostas na Fase de Recomendações, não foram implementadas. Logo, não se pode assegurar, de forma plena, que essas ações conduziram a melhora do desempenho do programa de Treinamento da DEAP, passando do nível comprometedor para o nível de excelência.

Outra limitação, seria que o modelo constituído foi elaborado para o Programa de Treinamento da DEAP, sendo que sua replicação integral não é estimada pelas pesquisadoras. A replicação integral é incompatível com os pressupostos da metodologia MCDA-C e da pesquisa qualitativa.

Por fim, sugere-se, para futuras pesquisas, a execução da Fase de Avaliação e o acompanhamento temporal do desempenho desse modelo, tanto quanto a aplicação da metodologia MCDA-C em outros Programas de Treinamento das escolas de governo, especialmente na modalidade de Ensino a Distância. Desse modo, pode-se averiguar as 
particularidades e similaridades desses Programas a Distância. Também, recomenda-se o uso desta metodologia para as modalidades de ensino presenciais.

Sugere-se, inclusive, testar a construção de modelo de avaliação com outros da literatura como o IMPACT e o modelo lógico que é usado para avaliação de programas de modo geral.

\section{REFERÊNCIAS}

Abbad, G. S., Corrêa, V. P., \& Meneses, P. P. M. (2010). Avaliação de treinamentos a distância: relações entre estratégias de aprendizagem e satisfação com o treinamento. RAM. Revista de Administração Mackenzie, 11(2), 43-67.

Al-Athari, A., \& Zairi, M. (2002). Training evaluation: an empirical study in Kuwait. Journal of European Industrial Training, 26(5), 241- 251.

Alvarez, K., Salas, E., \& Garofano, C. M. (2004). An integrated model of training evaluation and effectiveness. Human Resource Development Review, 3(4), 385-416.

Costa, C. A. B. (1992). Structuration, construction et exploitation d'un modèle multicritère d'aide à la décision. (Tese de doutorado). Instituto Superior Técnico, Universidade Técnica de Lisboa, Lisboa.

Birdi, K. S. (2005). No idea? Evaluating the effectiveness of creativity training. Journal of European Industrial Training, 29(2), 102-111.

Bititci, U., Garengo, P., Dörfler, V., \& Nudurupati, S. (2012). Performance measurement: Challenges for tomorrow. International Journal of Management Reviews, 14(3), 305-327.

Bortoluzzi, S. C., Silva, M., R., Ensslin, S. R., \& Ensslin, L. (2013). Estruturação de um modelo de Avaliação de Desempenho para a gestão do curso de Ciências Contábeis da Universidade Tecnológica Federal do Paraná. Revista de Educação e Pesquisa em Contabilidade, 7(1), 36- 57

Camolesi, D., \& Cremonezi, G. O. G. (2015). Avaliação dos programas de treinamento e mapeamento de competências em uma serventia prestadora de serviços públicos com administração privada. Revista Administração em Diálogo, 17(2), 185-210.

Carvalho, R. S., \& Abbad, G. (2006). Avaliação de treinamento a distância: reação, suporte à transferência e impactos no trabalho. Revista de Administração contemporânea, 10(1), 95116.

Coelho Junior, F. A., \& da Silva Abbad, G. (2010). Construção e validação de uma escala de avaliação de impacto em profundidade de um treinamento a distância em uma organização do setor bancário brasileiro. REAd-Revista Eletrônica de Administração, 16(1), 91-119.

Curado, C., \& Teixeira, S. M. (2014). Training evaluation levels and ROI: The case of a small logistics company. European Journal of Training and Development, 38(9), 845-870.

Dias, D. M., \& Guimarães, M. G. V. (2016). Avaliação do Impacto da Capacitação Profissional no Âmbito da Prefeitura de Manaus por meio da Aplicação do Modelo Impact. Perspectivas em Gestão \& Conhecimento, 6(1), 200-222.

Ensslin, S. R., Amaral, B. G., Valmorbida, S. M. I., \& Dutra, A. (2018). Public Management: Formation of a Constructivist Model to Support the Virtual School of Public Administration of Santa Catarina in Combating the Evasion of Distance Learning. Iberoamerican Journal Of Strategic Management (IJSM), 17(4), 90-110. 
Ensslin, S. R., Ensslin, L., Imlau, J. M., \& Chaves, L. C. (2014). Processo de mapeamento das publicações científicas de um tema: portfólio bibliográfico e análise bibliométrica sobre Avaliação de Desempenho de cooperativas de produção agropecuária. Revista de Economia e Sociologia Rural (Impresso), 52, 587-608.

Ensslin, L., Dutra, A., \& Ensslin, S. R. (2000). MCDA: a constructivist approach to the management of human resources at a governmental agency. International Transactions in Operational Research, 7(1), 79- 100.

Getha-Taylor, H., Fowles, J., Silvia, C., \& Merritt, C. C. (2015). Considering the Effects of Time on Leadership Development: A Local Government Training Evaluation. Public Personnel Management, 44(3), 295-316.

Ghosh, P., Joshi, J. P., Satyawadi, R., Mukherjee, U., \& Ranjan, R. (2011). Evaluating effectiveness of a training programme with trainee reaction. Industrial and Commercial Training, 43(4), 247-255.

Grohmann, A., \& Kauffeld, S. (2013). Evaluating training programs: Development and correlates of the Questionnaire for Professional Training Evaluation. International Journal of Training and Development, 17(2), 135-155.

Healy, P. (2001). Training and public sector reform: An integrated approach. Public Administration and Development, 21(4), 309-319.

Hillen, C., Laffin, M., \& Ensslin, S. R. (2018). Proposições sobre formação de professores na área Contábil. Arquivos Analíticos de Políticas Educativas, 26(106), 1-30.

Honeycutt, E. D., \& Stevenson, T. H. (1989). Evaluating sales training programs. Industrial Marketing Management, 18(3), 215-222.

House, R. J., \& Tosi, H. (1963). An experimental evaluation of a management-training program. Academy of Management Journal, 6(3), 303-315.

Huque, A. S., \& Vyas, L. (2008). Expectations and performance: Assessment of public service training in Hong Kong. International Journal of Human Resource Management, 19(1), 188-204.

Jeschke, K. C., Kines, P., Rasmussen, L., Andersen, L. P. S., Dyreborg, J., Ajslev, J., Kabel, A., Jensen, E., \& Andersen, L. L. (2017). Process evaluation of a Toolbox-training program for construction foremen in Denmark. Safety Science, 94, 152-160.

Kirkpatrick, D. L. (1979). Techniques for Evaluating Training Programs. Training and Development Journal, 33(6), 78-92.

Kucherov, D., \& Manokhina, D. (2017). Evaluation of training programs in Russian manufacturing companies. European Journal of Training and Development, 41(2), 119143.

Kuprenas, J. A., Madjidi, F., \& Alexander A. S. (1999). A Project Management Training Program. Journal of Management in Engineering, 15(6), 47-55.

Lee, C., Jean, D., Kim, W., \& Lee, J. (2017). Evaluating Training for New Government Officials: A Case Study Using the Success Case Method. Public Personnel Management, 46(4), 419-444.

Likert, R. (1932). A technique for the measurement of attitudes. Archives of Psychology, 22(140), 1-55. 
Lingham, T., Richley, B., \& Rezania, D. (2006). An evaluation system for training programs: A case study using a four-phase approach. Career Development International, 11(4), 334351 .

Lucas, R. I., Promentilla, M. A., Ubando, A., Tan, R. G., Aviso, K., \& Yu, K. D. (2017). An AHP-based evaluation method for teacher training workshop on information and communication technology. Evaluation and Program Planning, 63, 93-100.

Mann, S., \& Robertson, I. T. (1996). What should training evaluations evaluate? Journal of European Industrial Training, 20(9), 14-20.

Meneses, P. P. M., \& Abbad, G. (2009). Proposta para desenvolvimento de modelos de avaliação da efetividade de programas de treinamento. RAC-Eletrônica, 3(1), 105-122.

Moffie, D. J., Calhoon, R., \& O'brien, J. K. (1964). Evaluation of a management development program. Personnel Psychology, 17(4), 431- 440.

Muhaisen, A. S., \& Asour, O. S. (2017). Developing and Evaluating Training Programs on Energy Efficient Building Design: The IUG Experience, Palestine. Journal of Engineering Research \& Technology, 4(2), 43-47.

Neely, A., Gregory, M., \& Platts, K. (1995). Performance measurement system design - A literature review and research agenda. International Journal of Operations \& Production Management, 15(4), 80-116.

Portal da DEAPVirtual. Recuperado de http://deapvirtual2.sea.sc.gov.br/.

Portal do Servidor Público Estatual Estadual-SC Poder Executivo. Recuperado de http://www.portaldoservidor.sc.gov.br. Acesso em 19 de janeiro de 2018.

Rahim, S. A. (2017). Evaluation of the effectiveness of training programmes of Islami Bank Bangladesh Limited. Journal of Business and Retail Management Research, 11(3), 154164.

Richardson, R. J. (1999). Pesquisa social: métodos e técnicas. São Paulo: Atlas.

Roy, B. (1993). Decision science or decision-aid science. European Journal of Operational Research, 66(2), 184-203.

Sampieri, R. H., Collado, C. F., \& Lucio, P. B. (2013). Metodologia de pesquisa. Porto Alegre: Penso.

Saunders, R. P., Evans, M. H., \& Joshi, P. (2005) Desenvolvendo um plano de avaliação de processos para avaliar a implementação de programas de promoção da saúde: um guia prático. Prática de promoção da saúde, 2(6), 134-147.

Schröeder, C. D. S., Nakayama, M. K., Pilla, B. S., Haro, D. G., \& Binotto, E. (2005). Sistemas de treinamento corporativo virtual: definindo critérios e indicadores de avaliação. Revista Eletrônica de Administração, 11(1), 1-24.

Sims, R. R. (1993). Evaluating public-sector training-programs. Public Personnel Management, 22(4), 591-615.

Steensma, H., \& Groeneveld, K. (2010). Evaluating a training using the four levels model. Journal of Workplace Learning, 22(5), 319-331.

Suliyanto, W. N., \& Setyawati, S. M. (2015). Training program evaluation on batik micro small medium enterprises (MSMEs): An analytical hierarchy process (AHP) method. International Business Management, 9(3), 251-257. 
Tasca, J. E., Ensslin, L., \& Ensslin, S. R. (2012). A avaliação de programas de capacitação: um estudo de caso na administração pública. Revista de Administração Pública, 46(3), 647675.

Tasca, J. E., Ensslin, L., Ensslin, S. R., \& Alves, M. B. M. (2010). An approach for selecting a theoretical framework for the evaluation of training programs. Journal of European Industrial Training, 34(7), 631- 655.

Tennant, C., Boonkrong, M., \& Roberts, P. A. (2002). The design of a training programme measurement model. Journal of European Industrial Training, 26(5), 230-240.

Wang, G. G., \& Wilcox, D. (2006). Training evaluation: knowing more than is practiced. Advances in Developing Human Resources, 8(4), 528-539. 